\title{
Energy: An Exploratory Study on the Experience of Developing Countries in the Context of Development and the State of the Environment
}

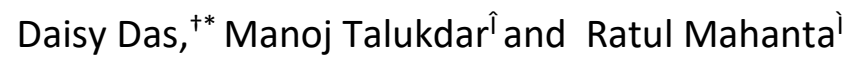

\section{Abstract}

Energy is required for development because it facilitates production and makes day to day activity less cumbersome. The industrial revolution and the progress after that would not have been possible without increased energy use. Issues related to energy use in developing countries are complicated. These countries use energy derived mostly from non-renewable sources such as petroleum, coal and inefficient fuels like firewood, and biomass. Thus, energy use leads to environmental pollution. Hence, policy measures aimed at the development imperative may conflict with policies relating to conserving the environment. Against this background, the paper tries to examine the relationship between energy use and development at the macro and micro levels and how energy use affects the environment. This study is exploratory and relies on traditional literature review. Our study relates to nonrenewable energy sources in the context of developing countries. We find that there is no uniformity of results in the relationship between energy use, development and the state of the environment. We recommend further studies to ascertain the causes of such inconclusiveness. At the household level, people are deprived of the assured and adequate supply of efficient fuels for domestic use. Hence, policy measures should strive to ensure ease of access to reliable and affordable energy sources as development proceeds.

Keywords: Growth Hypothesis, Feedback Hypothesis, Neutrality Hypothesis, Conservation Hypothesis, Energy Ladder, Fuel Stacking

\footnotetext{
${ }^{\dagger}$ Assistant Professor, Department of Economics, Cotton University, Guwhati-1, Assam , India

*Corresponding Author, Email: daisy.das@gmail.com

ÎAssociate Professor, Department of Economics, Cotton University, Guwhati-1, Assam , India, Email: manojkumar.talukdar@gmail.com

' Associate Professor, Department of Economics, Gauhati University, Email: rmeco@gauhati.ac.in (C) 2019 Das et al. This is an Open Access article distributed under the terms of the Creative Commons Attribution License (http://creativecommons.org/licenses/by/2.0), which permits unrestricted use, distribution, and reproduction in any medium, provided the original work is properly cited.
} 


\section{Introduction}

Humankind has been using energy since the beginning of life on earth. The primary source of energy for our predecessors was the sun which supplied energy directly or indirectly. In the course of time, humans could learn the use of other renewable and non-renewable energy sources on earth. Energy as a 'good' refers to different types of energy sources, including both renewable and non-renewable for the supply of power, necessary for the desired action. However, 'energy-as-a-service' refers to an emerging business model which deals with the management of customer's energy portfolio and related issues. Our study refers to the use of nonrenewable energy, which is used for industrial, commercial and domestic purposes.

With the advancement of mechanisation, energy consumption increases. It has been predicted that world energy consumption will grow by 30 per cent until 2040 (IEA, 2017). The significant share of this demand is likely to come from developing countries due to their professed goal of achieving higher levels of income, employment and socio-economic well being. It has been observed that developing countries can experience an improvement in their standard of living with increased energy use (Arto et al., 2016).

Although energy is crucial for development, mainstream economists have not given due recognition to energy consumption (Stern, 2014). They consider land, labour, capital and enterprise as primary factors of production. Energy goods have been considered as intermediary inputs in the production process. However, it is difficult to ignore the role of energy in the production process and allied economic activity if the laws of thermodynamics are taken into consideration. The first law of thermodynamics states that energy can neither be created nor destroyed. Energy has two components 'exergy' and 'anergy'. Exergy is a useful part of the energy which may be utilised for production. The residual from this process is called anergy. According to the second law of thermodynamics, the transformation of matter requires a minimum quantity of energy. As energy is transformed from one matter to another, the entropy or disorder increases in a closed system. Therefore, the production process has to use low entropy energy and discard high entropy materials like wastes into the evironmnent. ${ }^{1}$ Since exergy is wholly exhausted in the production process like any other factor, it should be considered a factor of production (Kummel et al., 2010; Ayres, 1998). The fact that all energy cannot be recycled to get back the original quantum of energy implies that in a closed system, the increased use of energy may be unsustainable in the future. Ecological economists have given due importance to the sustainable use of energy in economic growth and development.

Against these backdrops, this research seeks to explore the issue of energy use in developing countries. It discusses the issue of energy consumption and its relation to the environment and development. The use of energy is an essential issue because it is positively related to growth and pollution. To the best of our knowledge, the present study, based on an extensive survey of existing literature, is the first to examine the relationship between energy use, development and the environment, looking simultaneously at the macro and micro levels, in the setting of developing country experience.

The structure of the paper is as follows. The next section describes the review plan. The subsequent, section discusses the relationship between energy use and economic growth at the macro level. This section reviews studies related to developing countries. Following this, it explores the relationship between energy use and growth of income at the household level. This is followed by section where we discuss the relationship between energy use and the environment. The last section winds up the discussion with concluding remarks.

\footnotetext{
${ }^{1}$ The entropy of a system is measured by the temperature per unit which is lost while using energy
} 


\section{Review Plan}

This research is exploratory in nature, which tries to investigate the experiences of developing countries in the arena of energy use. Thus, we gain a broad understanding of the topic in exploratory research. The literature review is a research method which is commonly used in an exploratory study. Such study needs a flexible plan for the formulation of ideas and insights which is possible with the help of traditional literature review. It describes a phenomenon and provides a comprehensive picture of the problems (Jesson et al., 2011). The traditional literature review is not as rigorous as systematic literature review as it has to allow flexibility in an investigation of a research problem. Such type of review provides a scope to assess theories or hypotheses by critically examining methods and results of other primary studies with an emphasis on background and contextual material.

There is no predetermined criterion to select research articles for undertaking a traditional literature review. Initially, articles were selected with the help of keywords like 'energy', 'environment' and 'development'. Different studies that discuss the relationship between energy use and development have been drawn from across the world, but the majority of these relate to Asian countries (Zhang et al., 2012; Akhmat and Zaman, 2013; Ahmed and Long, 2014; Sehjpal et al., 2014; Cheng and Urpelainen, 2014; Behera, 2015; RECAP, 2017). We do not restrict the selection of articles to this region though Asian countries draw the attention of researchers for their high energy demand for the development and industrial activities (RECAP, 2017) and thus, there are plenty of articles that may be taken up for review. Besides, we have drawn studies on other developing countries depending on their contextual relevance. In traditional review choice of paper is purposive (Jesson et al., 2011) and one moves from one paper to another following up the lead. We have included peerreviewed published papers and working papers published by organisations of international repute like the Asian Development Bank, World Health Organisation, International Energy Agency and United Nations. Thus, there are 64 papers, all interwoven by threads of argument. The analysis and synthesis of the selected literature are purely discursive, which refers to the crucial paradigm or ideas prevailing in the arguments in a particular document. The traditional literature review does not require a methodological report. However, we have prepared diagrams and flow charts to present the content of the literature that has been surveyed. In the next section, we discuss energy use and development at the macro level.

\section{Energy Use and Development at the Macro Level}

Energy provides the motive force and makes mass production easy. The industrial revolution would not have been possible without energy. To understand the relationship between energy use and development, researchers commonly use four hypotheses: neutrality hypothesis, feedback hypothesis, conservation hypothesis and growth hypothesis (Ozturk, 2010; Apergis and Payne, 2011; Chen et al., 2007; Yoo, 2006). These have been depicted in Figure 1. 


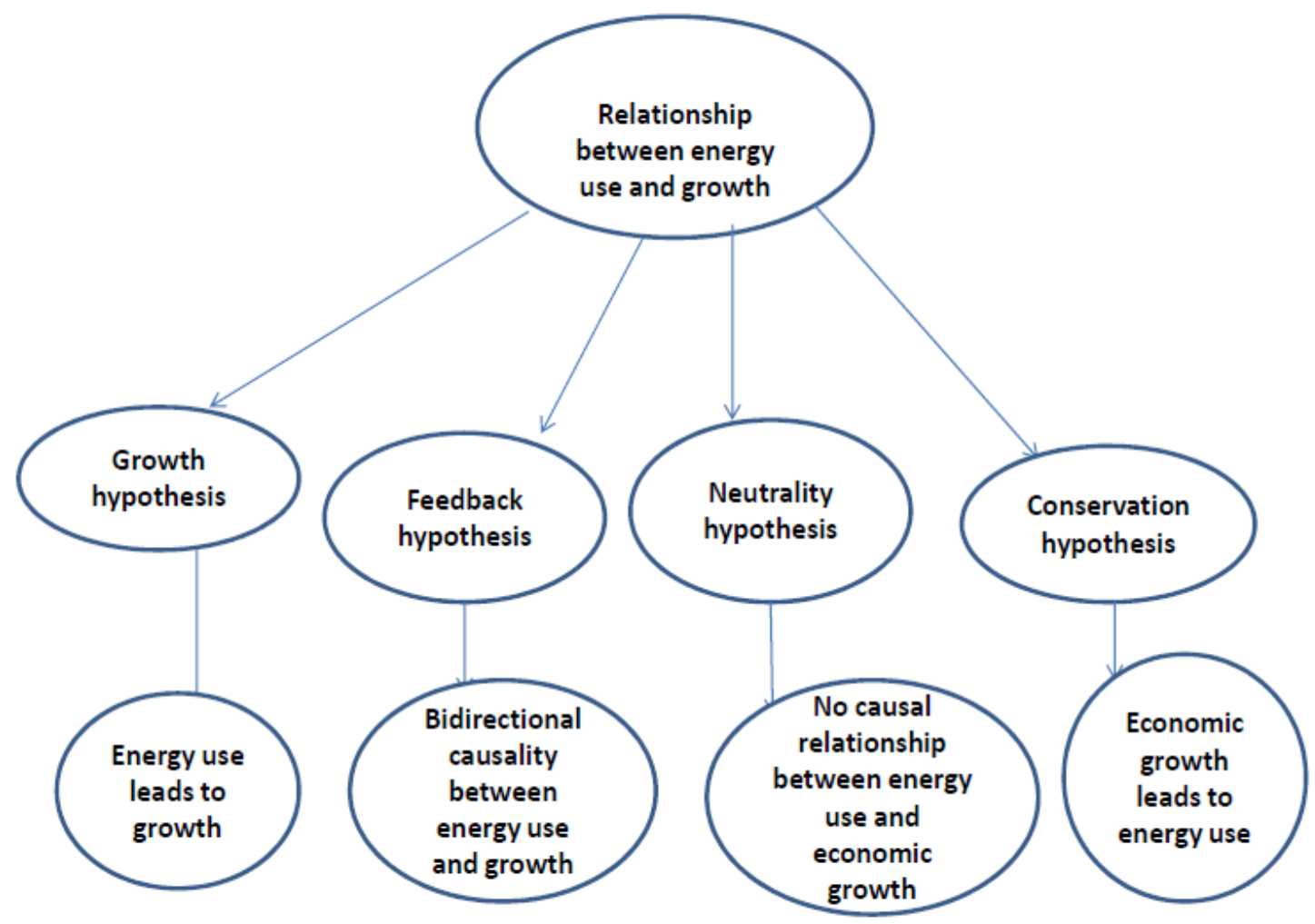

Figure 1: Relation between Energy use and Growth

Source: Constructed by the Authors with Inputs from Review

The neutrality hypothesis holds that there is no causal relationship between economic growth and energy consumption. In other words, neither economic growth will cause an increase in energy consumption, nor will energy consumption generate economic growth. Thus, energy does not play an vital role in economic growth, and any related conservation measures will not hamper production related activities (Chen et al., 2007). Contrary to this, the feedback hypothesis describes a two-way causality between energy consumption and economic growth. This hypothesis reinforces a mutual dependence between growth and energy use and any action aimed at energy conservation may adversely affect economic growth if an adequate supply of energy is not ensured in advance (Shahbaz et al., 2012).

The conservation hypothesis postulates that economic growth leads to energy consumption, and this relationship is unidirectional and not vice versa (Nasreen et al., 2014). This means that the economic development of a nation is not much dependent on the use of energy. As a result, energy conservation policies will not affect growth adversely. The reverse is the case with growth hypothesis. This hypothesis postulates that energy consumption leads to economic growth and an effort to minimise energy use will hamper economic growth (Wolde-Rufael, 2006).

The relationship between economic growth and energy use has been extensively studied in the last couple of decades. Asian countries are found to have exhibited bidirectional causality (Nasreen and Anwar, 2014), but evidence from South Asian countries tends to support the neutrality hypothesis (Akhmat and Zaman, 2013). Other studies found a neutral relationship between economic growth and energy use (Masih and Masih, 1996; Soytas and Sari, 2003).

While exploring the relationship between economic growth and energy consumption, it was found that there was no uniformity across among developing countries regarding the causality between energy use and growth (Apergis and Payne, 2011; Shahateet, 2014; 
Wolde-Rufael, 2006; Behera, 2015). Even for the same country, results were found to differ across studies. For example, the experience of India vindicated the conservation hypothesis (Behera, 2015). On the contrary, the neutrality hypothesis has also been observed in the case of India (Ghosh, 2010). Yet other studies found bidirectional causality between energy consumption and GDP (Soytas and Sari, 2003; Paul et al., 2004; Gollagari and Rena, 2013). The inconsistencies in these finding may have arisen due to the use of different datasets about alternate periods and the use of different statistical/econometric tools. Such nonconclusiveness on the relation between energy use and growth at the macro level in the case of developing countries may create problems while approaching the task of policy formulation. In the following section, the use of energy and development at the household level is discussed.

\section{Energy Use and Development at the Household Level}

The household sector plays a vital role in determining energy consumption as it accounts for 29 per cent of the economy's energy consumption and contributes to 21 per cent of total carbon emissions (UN, 2016). A significant part of the total energy consumption at the household level is accounted for by noncommercial sources consisting of fuelwood, animal and agricultural wastes and other sources. Such type of energy use may not be sustainable in the long run (Zhou et al., 2008).

With an increase in income, households are expected to shift to superior fuels like LPG or electric cook stove. Thus, transit from traditional fuels and cooking stoves to modern fuels and cooking technology. Households, during the transition phase, consume inefficient fuels such as charcoal and kerosene. When households prefer superior fuel to inferior fuel one after another along a vertical scale, the phenomenon is called 'energy ladder'. This phenomenon is predicted based on the 'economic theory of consumers' behaviour' which is consistent with the neoclassical theory where the consumer progressively moves on to, more sophisticated energy carriers as income increases (Hosier and Dowd, 1987 ). This is shown in Figure 2.

The understanding of the concept requires using some concepts of microeconomics. The 'energy ladder' hypothesis assumes that modern and cleaner fuels are normal goods, and traditional fuels are inferior goods. 'Goods' in economics are materials having a utility which satisfies human wants and energy is a 'good' because it has utility. Fuel is a normal good (say, LPG, biogas) when its demand increases with a rise in income. The reverse is the case with inferior fuels (say, kerosene, firewood, coal ) and demand for such commodity declines when income increases (Maddala, 2004). 


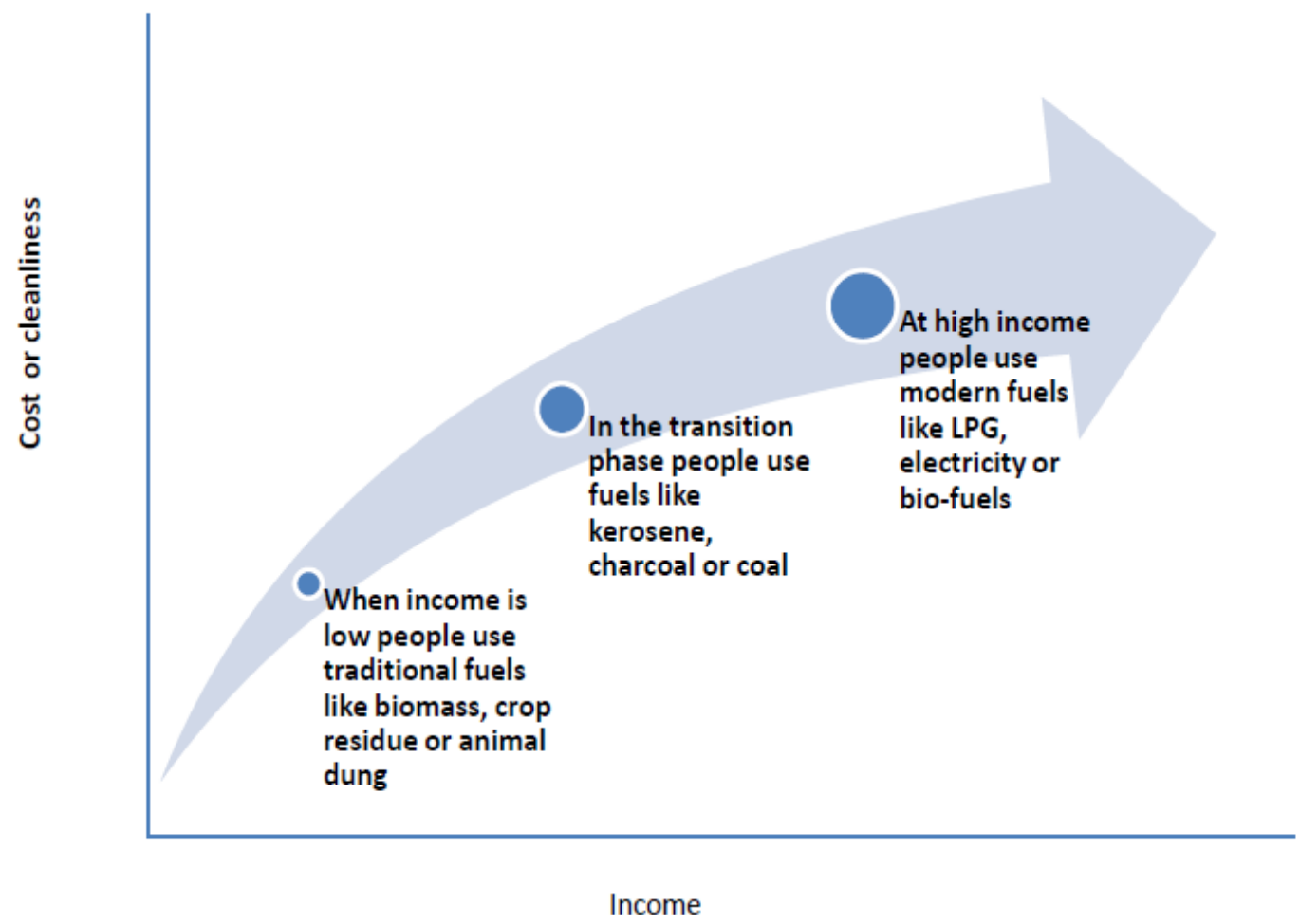

Figure 2: Energy ladder hypothesis

Source: Constructed by the Authors with Inputs from Review

Interestingly, evidence from the literature shows that households in developing countries do not climb the energy ladder when income increases; instead, they tend to consume a combination of fuels for cooking and lighting. Thus, instead of moving up the ladder step by step with increasing incomes, they choose a combination of fuels, which is known as fuel stacking. This phenomenon of fuel stacking is peculiar to developing countries and has gained attention during the last two decades.

At the household level, energy demand may be determined by economic, geographic, housing and demographic characteristics (Pachauri, 2004; IEA, 2006; Hosier et al., 1993) as well as by natural factors like temperature (Xiaohua and Jingfei, 2005). To some extent, socio-cultural factors also play an essential role in determining household energy choice (Ogwumike et al., 2014; Sehjpal et al., 2014; Akpalu et al., 2011; Ngui et al., 2011; Peng et al., 2010; Masera and Navia, 1997). In rural areas of developing countries, modern fuels play a relatively modest role and are often confined to the top income groups (Heltberg, 2004). For example, in Mexico, people prefer firewood for cooking traditional items despite having access to modern energy (Masera et al., 2000). This indicates that household with increased income may not automatically climb up the energy ladder. Rather, people tend to use combinations of energy sources, each for a particular purpose, instead of completely abandoning a particular type of energy (Horst and Hovorka, 2008). Some studies find a non-linear relationship between income and fuel choice in India and Ethiopia (Rao and Reddy, 2007; Abebaw, 2007). When such relationship is non-linear, it may take the shape of an elongated ' $\mathrm{S}$ ' or a ' $\mathrm{U}$ ', and the average consumption of firewood or any traditional energy becomes very low at a threshold level of income. With an increase in income, people may prefer to use modern energy. Beyond a certain increase in income, the elasticity of demand for energy declines. This phenomenon resembles the classic case of the Engel Curve, which describes how expenditure on a household item changes with income.

Thus, it is difficult to conclusively affirm that people use modern energy for cooking as income grows. People stack fuels for lighting as well. Almost 1.2 billion people in the world do 
not have access to electricity and the supply of electricity to connected households is erratic (IEA, 2019). For lighting, people prefer electricity, but they have to store kerosene or other standby sources due to the unreliable supply of electricity in most developing countries (Muller and Yan, 2016). In areas where electricity supply is not feasible, people use solar or distributed generation of electricity from renewable sources.

\section{Energy Use and Environmental Pollution}

Developing countries mostly use fossil fuels like petroleum, coal, and natural gas or biomass and the share of renewable energy is negligible in their total energy consumption (IEA, 2019). However, developed countries are no exception to this phenomenon as they too depend on nonrenewable energy. Use of fossil fuel emits carbondioxide $\left(\mathrm{CO}_{2}\right)$ and other noxious elements into the environment. While discussing the relationship between energy consumption and the environment, researchers often use the concept of the Environmental Kuznets curve (EKC). The EKC hypothesises an inverted $U$ shaped curve in which pollution related parameters are plotted against per capita income. The EKC is based on the original Kuznets curve, which describes the relationship between economic growth and income inequality (Kuznets, 1955). When a country tries to achieve growth, it has to increase its productive capacity and so the increase in energy usage (Figure 3 ). Thus a country is producing pollution rapidly until the country reaches the middle-income stage and after that, as the country's income increases it could reduce the emission of pollution through the use of various control and command policies as well as market intervention.

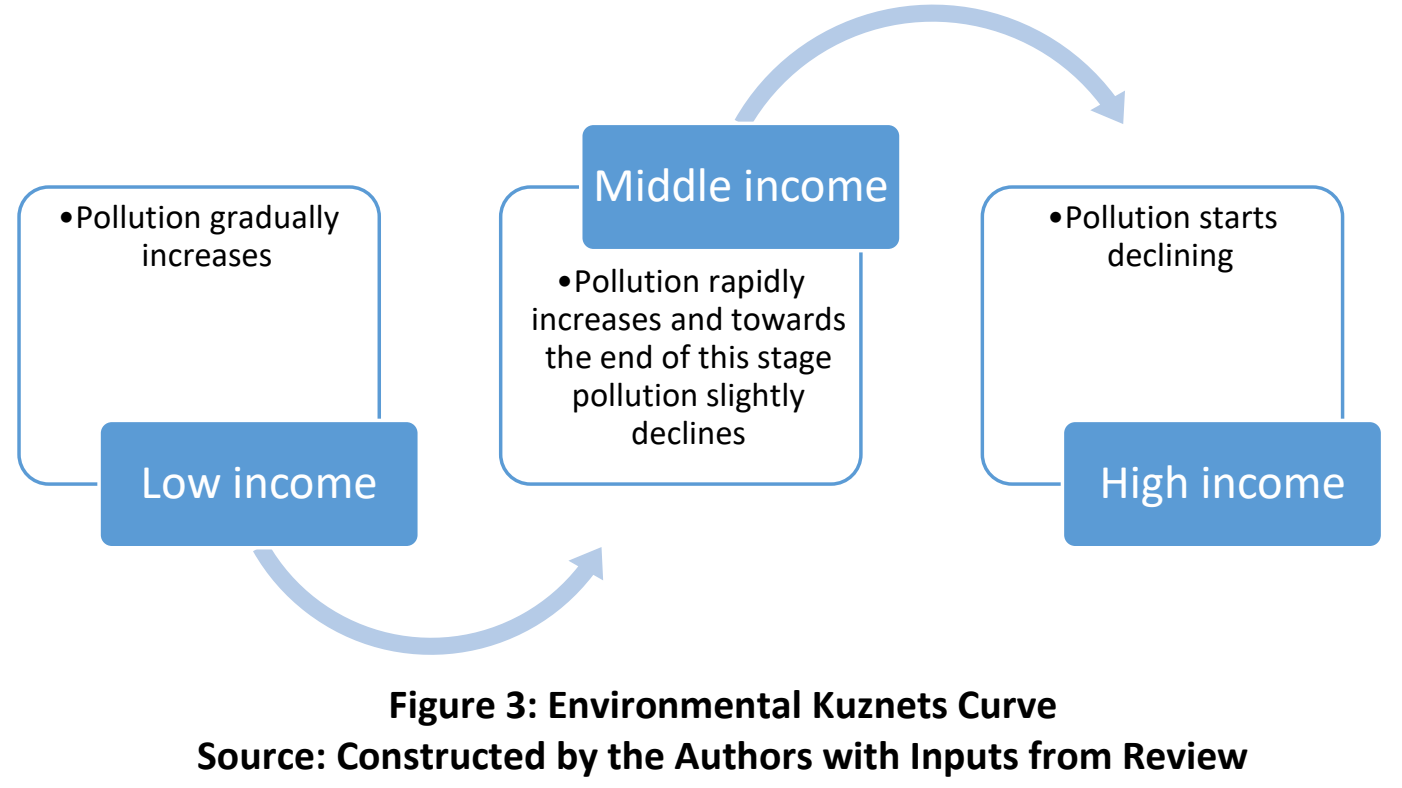

For those countries where gross national income per capita is $\$ 995$ or less, there exists hardly any study because researchers may not have discerned any causal relationship between growth and $\mathrm{CO}_{2}$ emission precisely because of their low rates of growth and level of industrialisation. ${ }^{2}$ Therefore, these countries

\footnotetext{
2 Grouping of countries to discuss the EKC relation in developing countries have been taken from the World Bank. It classifies countries of the world into low income,
}

have been studied with the help of a panel, which includes several countries taken together. In a group of 32 Latin American and Caribbean countries, Al mulali et al. (2013) find that 60 per cent of the countries taken up in their study revealed a bidirectional relationship between energy consumption, economic growth and $\mathrm{CO}_{2}$

lower middle income, upper middle income and high income countries. But World Bank does not divide countries into groups in terms of level of development. 
emission though they did not vindicate the EKC hypothesis. It may well have been that these low-income countries had started emphasising on the service sector or tourism for growth and sustainability. For instance, there is a significant growth in the service sector in certain lower income Asian countries such as Bangladesh, Nepal, Cambodia, Vietnam etc (Estrada et al., 2013). In other words, economic development is not energy intensive in these countries. Therefore, the results are not conclusive of the relationship between economic growth and $\mathrm{CO}_{2}$ emission in lowincome countries.

The results are mixed for those countries whose gross national income per capita is between $\$$ 996 and \$ 3895 (Saboori and Sulaiman, 2013; Pardo and Ruiz, 2012; Freitas et al., 2011; Narayanan et al., 2010; Ozturk, 2010). They are clubbed as lower-middle-income countries, and EKC did not describe the experience of any of these countries except for Pakistan and the Democratic Republic of Congo. Hence, here, too, the results are not conclusive of the relationship between economic growth and $\left(\mathrm{CO}_{2}\right)$ emission. However, we get contrasting results for the upper-middle-income countries whose gross national income per capita ranges between $\$ 3,896$ and $\$ 12,055$. We find that there exists an EKC type of relation between energy use and pollution (Sharma, 2010; Robalino-Lopez et al., 2014; Mensah, 2014). One new hypothesis has been found for South Africa in which emission causes economic growth (Mensah, 2014). It is true that South Africa has a sizeable industrial base consisting mainly of a high-intensity mining sector which needs ample amounts of energy. For Mexico, Sheinbaum-Pardo et al. (2012) find that the manufacturing sector was the major contributor to $\mathrm{CO}_{2}$ emissions. Sharma (2011) finds that besides per capita GDP, trade openness too causes $\mathrm{CO}_{2}$ emission. The relation between $\mathrm{CO}_{2}$ emission and energy use after globalisation in India mirrors EKC (Vidyarthi, 2013; Murthy, 2012). In India, carbon emission is highly elastic with respect to real per capita income and energy use (Shahbaz et al., 2014; Kanjilal et al., 2013). The situation demands policy measures for sustainable development strategies. Economic growth is responsible for $\mathrm{CO}_{2}$ emission in China (Zhang et al., 2012). Energy use leads to the growth of output, but at the same time, it causes pollution. Jalil et al. (2009) examine the EKC relationship for $\mathrm{CO}_{2}$ emissions for China during 1971-2005 by using per capita $\mathrm{CO}_{2}$ emission as an indicator of environmental quality. The study confirms the existence of EKC for $\mathrm{CO}_{2}$ emission in China. A similar relationship between $\mathrm{CO}_{2}$ emission and energy use has been found for Pakistan as well (Ahmed and Long, 2014).

Thus, it has been found that the relation between energy use and environmental pollution is not uniform among developing countries at the macro level. However, at the level of the household, the use of inefficient fuel sources causes pollution. Fuelwood is the primary source of indoor air pollution and subsequent illness (Malla, 2013). Almost 3 billion people who are mostly living in low and middleincome countries use biomass, coal, dung cake or kerosene for cooking. Nearly 4 million of these people die from indoor air pollution-related diseases caused by burning of inefficient fuels (WHO, 2018).

\section{Conclusion}

The main contribution of the paper lies in exploring the relationship between energy, environment and development. From the preceding analysis, we see that despite having similarity in the pattern of energy use and the level of development nothing can be precisely stated about the relationship between energy use and development based on existing literature. The lack of uniformity in this context could be due to use of different econometric techniques or choice of data (panel or time series data). The same conundrum has been observed at the household level, where we find that the energy ladder hypothesis may not be applicable to developing countries. Instead, people prefer energy stacking due to the ease of access to solid biomass, technological backwardness and typical hassles relating to accessibility to assured supply of efficient and modern sources of fuel, for instance, electricity (Kroon, 2013). 
Similar is the case for the relation between energy use and pollution. In countries with low income, there is no well-defined relationship between energy use and pollution at the macro level. However, developing countries in the upper-middle-income group have been found to follow the EKC type of relationship. At the micro level, energy use causes indoor air pollution because people in developing countries are not only income poor but also energy poor (Pachauri et al., 2004) and they do not have access to the reliable and sustainable supply of energy.

However, the prevalence of the phenomenon of fuel stacking and indoor air pollution indicates that people in developing countries are deprived of efficient fuels like LPG and electricity. The energy market is often distorted in developing countries due to the presence of subsidy (Sovacool and D'Agostino, 2012) and the power sector is often plagued by ongoing theft, corruption, and there is a market failure in the energy sector (Chaurey et al., 2012). All these factors lead to market failure in the energy market. Such market imperfections can be reduced, to a great extent, by allowing private players to operate in the market. This will ensure not only efficient pricing but also other benefits from competition, such as a reduction in cost and easy availability. Energy poverty can be sustainably reduced to a great extent by the use of renewable energies. A few developing countries have sporadically used solar panels for lighting or biogas for cooking (Sovacool and Vivoda, 2012).

The inconclusive evidence at the macro level indicates that energy use is a tricky issue in developing countries. Therefore, there is a need for further research on energy use. Such studies should consider each country individually instead of taking a panel of countries. Studies may take into consideration the issue of energy demand and supply, sustainable growth and energy, prospects of renewable energy and regional trade in energy and other commodities based on a country's comparative advantage. There is a need for undertaking meta-analyses to examine this relationship. It remains to be examined as to why there is a lack of uniformity in results among countries. Further, analyses must proceed to seek explanations as to why other studies come up with differing results for any given study. By doing so, a cogent policy framework may be proposed which may form the bedrock of an efficient planning mechanism geared to the conservation of energy and its efficient use.

\section{References}

Abebaw, D. (2007). Household determinants of fuel wood choice in urban Ethiopia: a case study of Jimma town. The Journal of Developing

Areas, 117-126

Ahmed, K. and Long, W. (2014). Environmental Kuznets Curve and Pakistan: An Empirical Analysis. Procedia Economics and Finance 1, 413

Akhmat, G. and Zaman, K. (2013). Nuclear energy consumption, commercial energy consumption and economic growth in South Asia: bootstrap panel causality test. Renewable and Sustainable Energy Reviews, 25, 552-559

Akpalu, W., Dasmani, I. and Aglobitse, P. B. (2011). Demand for cooking fuels in a developing country: To what extent do taste and preferences matter? Energy Policy, 39(10), 6525-6531

Al-Mulali, U., Fereidouni, H. G., Lee, J. Y. and Sab, C. N. B. C. (2013). Examining the bidirectional long run relationship between renewable energy consumption and GDP growth. Renewable and Sustainable Energy Reviews, 22, 209-222

Apergis, N. A. and Payne, J.E. (2011). A dynamic panel study of economic development and the electricity consumption-growth nexus, Energy Economics, 33, 770-781

Arto, I., Perez, I., LAgo, R. and Bermejo, R. (2016). The energy requirements of a developed world. Energy for Sustainable Development, 33, 1-13

Ayres, R. U. (1998). Eco-thermodynamics: economics and the second law. Ecological Economics, 26, 189-209 
Behera, J. (2015). 'Examined the energy-led growth hypothesis in India: Evidence from time series analysis contribution/originality'. Energy Economics Letters, 2(24), 46-65

Chaurey, A., Krithika, P., Palit, D., Rakesh, S., and Sovacool, B. (2012). New partnerships and business models for facilitating energy access. Energy policy, 47, 48-55.

Chen, S.T., Kuo, H. I., and Chen, C. (2007). The relationship between GDP and electricity consumption in 10 Asian countries. Energy Policy, 35, 2611-2621

Cheng, C. and Urpelainen, J. (2014). Fuel stacking in India: Changes in the cooking and lighting mix, 1987-2010. Energy, 76(1), 306-317

Estrada, G., Acharya, Y., Batten, A., Brimble, P., Doung, P., Gulamov, M., Hossain, M., Mellor, D., Park, D. and Rahman, S. (2013). The service sector in lower income Asian economies. Asian Development Bank Working paper series.

Available at www.adb.org

Freitas, L.C., and Kaneko, S. (2011).

Decomposing the decoupling of $\mathrm{CO} 2$ emissions and economic growth in Brazil. Ecological Economics, 70, 1459-1469

Ghosh, S. (2010). Examining carbon emissions economic growth nexus for India: A multivariate cointegration approach. Energy Policy, 38, 3008-3014

Gollagari, R., G. and Rena, R. (2013). An empirical analysis of energy consumption and economic growth in India: are they casually related? Studia Oeconomica, 58(2): 22-40

Heltberg, R. (2004). Fuel switching: evidence from eight developing countries. Energy economics, 26(5), 869-887

Horst H.V., G. and Hovorka, A. J. (2008). Reassessing the "energy ladder": household energy use in Maun, Botswana. Energy Policy, 36(9), 3333-3344

Hosier, R. H. and Dowd, J. (1987). Household fuel choice in Zimbabwe: an empirical test of the energy ladder hypothesis. Resources and energy, 9(4), 347-361
Hosier, R. H., Mwandosya, M. J. and Luhanga, M. L. (1993). Future energy development in Tanzania: the energy costs of urbanization. Energy policy, 21(5), 524-542

IEA (2006). 'World Energy Outlook 2006', Outlook, p. 600pp. doi: 10.1787/weo-2006-en.

IEA (2019). Statistics Global energy data at your fingertips. https://www.iea.org. Accessed on 15.03.19

Jalil, A. and Mahmud, S. (2009).Environment Kuznets curve for $\mathrm{CO} 2$ emissions: $A$ cointegration analysis for China. Energy Policy $37,5167-5172$

Jesson, J., Matheson, L. and Lacey, F. M. (2011). Doing your literature review: Traditional and systematic techniques. Sage, London

Kanjilal, K. and Ghosh, S. (2013). Environmental Kuznet's curve for India: Evidence from tests for cointegration with unknown structuralbreaks. Energy Policy, 56, 509-515

Kroon, V.D., B., Brouwer, R. and Van Beukering, P. J. (2013). The energy ladder: Theoretical myth or empirical truth? Results from a metaanalysis. Renewable and Sustainable Energy Reviews, 20, 504-513

Kümmel, R., Ayres, R. and Lindenberger, D. (2010). Thermodynamic laws, economic methods and the productive power of energy. J. Non-Equilib. Thermodyn. 35, 145-179

Kuznets, S. (1955). Economic Growth and income inequality. American Economic Review, 45: $1-28$

Maddala, G.S. (2004). Microeconomics: Theory and Applications. Tata McGraw-Hill Education, India

Malla, S. (2013). Household energy consumption patterns and its environmental implications: Assessment of energy access and poverty in Nepal. Energy policy, 61, 990-1002

Masera, O. and Navia, J. (1997). Fuel switching or multiple cooking fuels? Understanding interfuel substitution patterns in rural Mexican households. Biomass and Bioenergy, 12(5), 347361 
Masera, O. R., Saatkamp, B. D. and Kammen, D. $M$. (2000). From linear fuel switching to multiple cooking strategies: a critique and alternative to the energy ladder model. World development, 28(12), 2083-2103

Masih, A. M. and Masih, R. (1996). Energy consumption, real income and temporal causality: results from a multi-country study based on cointegration and error-correction modelling techniques. Energy economics, 18(3), 165-183

Mensah, J.T. (2014). Carbon emissions, energy consumption and output: A threshold analysis on the causal dynamics in emerging African countries. Energy Policy, 70, 172-182

Muller, C. and Yan, H.(2016). Household fuel use in developing countries: Review of theory and evidence, halshs-01290714, https://halshs.archives-ouvertes.fr/halshs01290714/document

Murthy, I. K. (2012). A causal study between electricity consumption and CO 2 emissions in India. Prabandhan: Indian Journal of Management, 5(7), 43-52

Narayan, P.K. and Narayan, S. (2010). Carbon dioxide emissions and economic growth: Panel data evidence from developing countries. Energy Policy, 38, 661-666

Nasreen, S., and Anwar, S. (2014). Causal relationship between trade openness, economic growth and energy consumption: a panel data analysis of Asian Countries. Energy Policy, 69, 82-91

Ngui, D., Mutua, J., Osiolo, H. and Aligula, E. (2011). Household energy demand in Kenya: An application of the linear approximate almost ideal demand system (LA-AIDS). Energy policy, 39(11), 7084-7094

Ogwumike U., Ozughalu, M. and Abiona, G.A.(2014). household energy use and determinants: evidence from Nigeria Fidelis $\mathrm{O}$. International Journal of Energy Economics and Policy, 4(2), 248-262

Ozturk, I.(2010). Literature survey on energygrowth nexus. Energy Policy, 38, 340-349
Pachauri, S. (2004). An analysis of crosssectional variations in total household energy requirements in India using micro survey data. Energy Policy, 32(15), 1723-1735

Pachauri, S. and Spreng, D. (2004). Energy use and energy access in relation to poverty. Economic and Political Weekly, 39 (3), 271-278

Pardo, C., S. and Ruiz, B. (2012). Energy context in Latin America. Energy, 40(1), 39-46

Paul, S. and Bhattacharya, R. N. (2004). CO2 emission from energy use in India: a decomposition analysis. Energy Policy, 32(5), 585-593

Peng, W., Hisham, Z. and Pan, J. (2010). Household level fuel switching in rural Hubei. Energy for Sustainable

Development, 14(3), 238-244

Rao, M. N. and Reddy, B. S. (2007). Variations in energy use by Indian households: an analysis of micro level data. Energy, 32(2), 143-153

RECAP (2017). Energy consumption: The Asian Experience. http://recap.asia/climateasia/Energy-Consumption.html. Accessed on 22.04.19

Robalino-López, A., Garcia-Ramos, J.E., Golpe, A.A., Mena-Nieto, Á. (2014). System dynamics modelling and the environmental Kuznets curve in Ecuador (1980-2025). Energy Policy, 67, 923931.

Robalino-López, A., Mena, A., Garcia-Ramos, J. and Golpe, A. (2014). Studying the relationship between economic growth, $\mathrm{CO} 2$ emissions, and the environmental Kuznets curve in Venezuela (1980-2025). Renewable and Sustainable Energy Reviews. 41 ( C), 602-614

Sahoori, B. N. and Sulaiman, J. (2013).

Environmental degradation, economic growth and energy consumption: Evidence of the environmental Kuznets curve in Malaysia, Energy Policy, 60, 892-905

Sehjpal, R., Ramji, A., Soni, A. and Kumar, A. (2014). Going beyond incomes: Dimensions of cooking energy transitions in rural India. Energy, 68, 470-477 
Shahateet, M. I. (2014). Modeling economic growth and energy consumption in Arab countries: Cointegration and causality analysis. International Journal of Energy Economics and Policy, 4(3), 349-359

Shahbaz, M., Uddin, G. S., Rehman, I. U. and Imran, K. (2014). Industrialization, electricity consumption and $\mathrm{CO} 2$ emissions in Bangladesh. Renewable and Sustainable Energy Reviews, 31, 575-586

Shahbaz, M., Zeshan, M. and Afza, T. (2012). Is energy consumption effective to spur economic growth in Pakistan? New evidence from bounds test to level relationships and Granger causality tests. Economic Modelling, 29, 2310-2319

Sharma, S. S. (2011). Determinants of carbon dioxide emissions: Empirical evidence from 69 countries. Applied Energy 88, 376-382

Sheinbaum-Pardo, C., Mora-Pérez, S. and Robles-Morales, G. (2012). Decomposition of energy consumption and $\mathrm{CO}_{2}$ emissions in Mexican manufacturing industries: Trends between 1990 and 2008. Energy for Sustainable Development 16, (1), 57-67

Sovacool, B. and Vivoda, V. (2012). A comparison of Chinese, Indian and Japanese perceptions of energy security, Asian Survey, 52(5), 949-969.

Sovacool, B.K. and D'Agostino, A.L. (2012). A comparative analysis of solar home system programmes in China, Laos, Mongolia and Papua New Guinea. Progress in Development Studies 12 (4), 315-335

Soytas, U. and Sari, R. (2003). Energy consumption and GDP: causality relationship in G-7 countries and emerging markets. Energy Economics, 25(1), 33-37
Stern, D.I. (2014). Economic growth and energy, Encyclopedia of Energy, 2, 35-51

U.N. (2016). Responsible consumption \& production: Why it matters.

https://www.un.org/sustainabledevelopment

Vidyarthi, H., (2013). Energy consumption, carbon emissions and economic growth in India. World Journal of Science, Technology and Sustainable Development, 10(4), 278-287

WHO, (2018). Household air pollution and health. Available at https://www.who.int. Accessed on 21.04.19

Wolde-Rufael, Y. (2006). Electricity consumption and economic growth: a time series experience for 17 African countries. Energy Policy, 34 (10), 1106-1114

Xiaohua, W. and Jingfei, L. (2005). Influence of using household biogas digesters on household energy consumption in rural areas - a case study in Lianshui County in China. Renewable and Sustainable Energy Reviews, 9(2), 229-236

Yoo, S.H., (2006). The causal relationship between electricity consumption and economic growth in the ASEAN countries. Energy Policy, 34, 3573-3582

Zhang, X., Han, J., Shihuai, H., Peng, H., Li, Y., Shen, G. and Zhang, Y. (2012). Evaluating the interplays among economic growth and energy consumption and $\mathrm{CO} 2$ emission of China during 1990-2007. Renewable and Sustainable Energy Reviews, 16, 65- 72

Zhou, P., Ang, B. W. and Poh, K. L. (2008). A survey of data envelopment analysis in energy and environmental studies. European journal of operational research, 189 (1), 1-18 